\title{
Distribution of 14 high risk HPV types in cervical intraepithelial neoplasia detected by a non-radioactive general primer PCR mediated enzyme immunoassay
}

\author{
Ingo Nindl, Beatrix Lotz, Rosemarie Kühne-Heid, Ulrich Endisch, Achim Schneider
}

\begin{abstract}
Aim-To evaluate the presence of high risk human papillomaviruses (HPV) in cervical smears showing intraepithelial neoplasia (CIN).

Methods-The presence of 14 high risk HPV was evaluated in 114 cervical smears with CIN of different degrees, by comparing a non-radioactive polymerase chain reaction (PCR) enzyme immunoassay (EIA) with conventional PCR followed by radioactive Southern blot hybridisation. General primer PCR amplicons detecting low risk and high risk HPV were typed for 14 different high risk HPV types (HPV 16, $18,31,33,35,39,45,51,52,56,58,59,66$, and 68) by a non-radioactive PCR-EIA. Virus load of HPV 16 positive CIN was assessed using the semiquantitative PCR-EIA.

Results-Histological evaluation confirmed CIN I in 49 cases (mean age 29.0 years, range 17 to 52 ), CIN II in 31 cases (mean age 30.8 years, 18 to 54 ), and CIN III in 34 cases (mean age 31.1 years, 16 to 57). The non-radioactive PCR-EIA showed an overall agreement rate of $90 \%$ ( $\kappa$ value 0.75 ) when compared with conventional general primer PCR followed by radioactive Southern blot hybridisation. High risk HPVs were detected in $47 \%$ of CIN I, $77 \%$ of CIN II, and $97 \%$ of CIN III $(p \leqslant 0.02)$. HPV types $39,51,56$, and 58 were found in CIN I exclusively (between $2 \%$ and $8 \%$ ). HPV 16 and HPV 31 were detected in $12 \%$ and $2 \%$ of CIN I, 35\% and $21 \%$ of CIN II, and $74 \%$ and $13 \%$ of CIN III, respectively $(p \leqslant 0.03$ and $p \leqslant 0.04)$. The virus load estimated by the semiquantitative PCR-EIA of HPV 16 was similar in CIN I, CIN II, and CIN III.

Conclusions-The PCR-EIA has high clinical sensitivity for detecting CIN II/III $(\mathbf{9 0} \%)$. There was a significantly higher prevalence rate of HPV 16 and 31 in CIN III than in CIN I and II.

(F Clin Pathol 1999;52:17-22)
\end{abstract}

Keywords: human papillomavirus; general primer PCR enzyme immunoassay; cervical intraepithelial neoplasia

Pathology, Friedrich

Schiller University

R Kühne-Heid

Correspondence to:

Dr Nindl.

email:

nindl@bach.med.uni-jena.de

Accepted for publication 25 August 1998 and anogenital cancer. ${ }^{1}$ More than $80 \mathrm{HPV}$ types have been classified. Of these, up to 45 different types infect the genital tract. ${ }^{2}$ The
Epidemiological and molecular biological studies have proved the causal association between genital HPV types are divided into low risk and high risk, on the basis of their phylogenetic relations ${ }^{3}$ and their association with benign or malignant cervical lesions. High risk HPV are associated with high grade cervical intraepithelial neoplasia (CIN II/III) and cancer. HPV types $16,18,31,33$, and 45 have been shown to be the most prevalent types in cervical cancers. ${ }^{3-5}$ Low risk HPV types (such as HPV 6, 11, 42, 43, and 44) occur mainly in benign condylomas or CIN I. ${ }^{5}$ Prevalence of high risk HPV is more than $90 \%$ in CIN II/III or cervical cancers, approximately $50 \%$ in CIN I, and between 5\% and $10 \%$ in women with negative cytology. ${ }^{67}$ Several studies have shown the relevance of HPV testing in clinical studies. HPV testing may augment cytology in screening programmes. ${ }^{8-10}$ In addition, women with the diagnosis of atypical squamous cells of undetermined significance (ASCUS) can be triaged, ${ }^{11}{ }^{12}$ and patients with CIN I may possibly be subdivided into progressors and regressors related to high risk HPV persistence. ${ }^{13}$ The prevalence rate of HPV 16 is twice as high in CIN II/III as in CIN I. ${ }^{514-16} \mathrm{~A}$ higher virus load of HPV 16 was found in CIN III than in CIN I by a semiquantitative polymerase chain reaction (PCR) system. ${ }^{17} 18$ Recently, Jacobs et al developed a new generation of a general primer (GP) $5+/$ biotinylated (bio) GP6+ mediated PCR enzyme immunoassay (EIA) for rapid detection of 14 high risk and six low risk HPV. ${ }^{19}$ Our study was designed to determine the various high risk HPV types in CIN in German women using this nonradioactive PCR-EIA, to compare its sensitivity with conventional general primer PCR followed by radioactive Southern blot hybridisation, and to estimate the virus load of HPV 16 in smears from CIN by the semiquantitative PCR-EIA.

\section{Methods}

PATIENTS

Between March 1996 and April 1997, 368 women, mean age 32.0 years (range 16 to 70 ), were referred to our colposcopy clinic because of an atypical cytological smear, positive colposcopy, or a positive high risk HPV result. Colposcopically directed biopsies were obtained from all these women. The tissue was fixed in formalin, embedded in paraffin, and haematoxylin and eosin staining was performed for light microscopic analysis. In this study histological classification was in accordance with the WHO recommendations ${ }^{20}$ and the CIN classification of Richart. ${ }^{21}$ In addition, we integrated the recently described histological criteria by Crum 
and Nuovo, ${ }^{22}$ where the expression of nuclear atypia in different grades of CIN is more important than discordance of epithelial maturation. CIN I corresponds to low grade squamous intraepithelial lesions (LSIL), and CIN II and III to high grade squamous intraepithelial lesions (HSIL). CIN lesions were confirmed in 114 of the 368 women. We did not evaluate normal tissue or tissue containing invasive carcinoma or atypical metaplasia. Further analysis is restricted to this cohort. In all women a cervical smear was taken with a cytobrush. Cells were exfoliated on a glass slide for cytology and the brush was then immersed in $5 \mathrm{ml}$ phosphate buffered saline (PBS). Cells were taken from the ectocervix and posterior fornix with a Dacrontipped swab and suspended in the same PBS solution that was used for HPV DNA detection.

GENERAL PRIMER PCR

The cervical specimen were vigorously vortexed and $5 \mathrm{ml}$ of the suspension was divided in two tubes each containing $2.5 \mathrm{ml}$ PBS and both were centrifuged for 10 minutes at $4000 \mathrm{~g}$. The supernatant was discarded and one tube with cells was stored at $-70^{\circ} \mathrm{C}$. The cell pellet of the second tube was resuspended in $0.5 \mathrm{ml}(10$ $\mathrm{mM}$ Tris $\mathrm{HCl} \mathrm{pH} 8.3,50 \mathrm{mM} \mathrm{KCl}) ; 100 \mu \mathrm{l}$ of this solution was transferred into a new tube heated at $95^{\circ} \mathrm{C}$ for 10 minutes and both samples were stored at $-70^{\circ} \mathrm{C}$ until $\mathrm{HPV}$ detection was performed.

For HPV analysis $10 \mu \mathrm{l}$ of the heated $100 \mu \mathrm{l}$ suspension were used for a general primer PCR. The general primers GP5+ and bioGP6+, which span a region of $140-150 \mathrm{bp}$ from the L1 open reading frame of a broad spectrum of HPV genotypes, were used in the general primer PCR, as described by de Roda Husman et $\mathrm{al}^{23}$ with the exception that the GP6+ primer was biotinylated (bioGP6+). The $50 \mu \mathrm{l}$ PCR reaction mixtures contained $10 \mu \mathrm{l}$ of pretreated suspension of cervical cells, $50 \mathrm{mM}$ $\mathrm{KCl}, 10 \mathrm{mM}$ Tris $\mathrm{HCl} \mathrm{pH} 8.3,200 \mu \mathrm{M}$ of each dNTP, $3.5 \mathrm{mM} \mathrm{MgCl}_{2}, 1$ unit of a thermostable DNA polymerase (Thermus aquaticus; Perkin Elmer-Cetus), and $50 \mathrm{pmol}$ of GP5+ and bioGP6+ primer. The mixtures were incubated for four minutes at $95^{\circ} \mathrm{C}$ for DNA denaturation, followed by 40 cycles of amplification using a PCR processor (Perkin Elmer). Each cycle included a denaturation step to $95^{\circ} \mathrm{C}$ for one minute, an annealing step to $40^{\circ} \mathrm{C}$ for two minutes (non-stringent conditions), and a chain elongation step to $72^{\circ} \mathrm{C}$ for 1.5 minutes. To ensure a complete extension of the amplified DNA, the final elongation step was prolonged for another four minutes.

Two samples containing distilled water were included as negative controls in each experiment, none of which showed successful amplification; and also two samples of $1 \mathrm{ng}$ and $10 \mathrm{ng}$ genomic DNA from SiHa cells as positive and sensitivity controls, which showed successful amplification in each experiment evaluated.

Ten microlitres of the general primer PCR mixtures were finally analysed by electrophoresis in $1.5 \%$ agarose gels. Each agarose gel contained a PCR amplicon of SiHa cells on all four edges (blot control) and two internal negative and two positive controls. The electrophoretically separated general primer PCR amplicons were blotted onto nylon membranes (Qiabrane, Qiagene) in $0.5 \mathrm{M} \mathrm{NaOH}, 1.5 \mathrm{M} \mathrm{NaCl}$ overnight. Thereafter, the membranes were saturated with $2 \times$ SSC $(1 \times$ SSC is $0.15 \mathrm{M}$ sodium phosphate ( $\mathrm{pH} 7.4$ ), 7\% SDS (sodium dodecyl sulphate), and $1 \mathrm{mM}$ EDTA).

Hybridisation was performed in the same solution supplemented with the denatured probe for $12-16$ hours at $55^{\circ} \mathrm{C}$. The general probe consisted of a mixture of the GP5+/ GP6+ PCR amplicons generated from cloned HPV 6, 11, 16, 18, 31, and 33, which were electrophoretically separated in NA agarose (Pharmacia), excised from the gel, and purified after freeze squeezing. A total of $2.5 \mathrm{ng}$ of a mixture of these purified DNAs was used to generate an $\left[\alpha-{ }^{32} \mathrm{P}\right] \mathrm{dCTP}$ random primed labelled general probe. The sensitivity of the general probe was between 0.1 and $1 \mathrm{ng} \mathrm{SiHa}$ DNA and at the subpicogram level of several cloned HPV plasmids, corresponding to 15 to 200 copies depending on the HPV type.

After hybridisation, the filters were washed three times for 15 minutes in $3 \times \mathrm{SSC} /$ $0.5 \% \mathrm{SDS}$ at $55^{\circ} \mathrm{C}$. Autoradiography was performed overnight at $-70^{\circ} \mathrm{C}$ with Kodak Royal $\mathrm{X}-\mathrm{Omat}$ film and intensifying screens. Samples showing a 140-150 bp product after hybridisation with the radioactive HPV general probe were HPV positive (GP+).

The radioactively labelled general probe detects a broad spectrum of at least 19 high risk/low risk genital HPV types. ${ }^{24}$ To test the quality of the cervical smears a separate PCR with $\beta$ globin specific primers PC03 (5'-ACACAACTGTGTTCACTAGC-3') and PC04 (5'-CAACTTCATCCACGTTCACC$\left.3^{\prime}\right)$ for each sample was included, and only samples with a positive reaction showing a 100 bp product were used in this study. PCR conditions were the same as described for the general primer PCR except that $25 \mathrm{pmol}$ of each primer, $1.5 \mathrm{mM} \mathrm{MgCl}_{2}$, and an annealing step of $55^{\circ} \mathrm{C}$ (stringent conditions) were used.

DETECTION OF HIGH RISK/LOW RISK HPV BY GENERAL PRIMER PCR-EIA

For EIA analysis, GP5+/bioGP6+ generated PCR amplicons were captured on streptavidin coated microwells (Boehringer Mannheim), denatured by alkaline treatment, hybridised with cocktails of DIG labelled internal specific oligonucleotide probes, and detected immunohistochemically by reading optical density values (OD $405 \mathrm{~nm}$ ) after overnight incubation. To ensure the high quality of type specific probes, we requested more than $90 \%$ labelling efficiency of each oligonucleotide, purified by reverse phase chromatography (Eurogentec). Fourteen different HPV type specific oligonucleotides were used to detect 14 high risk HPV types (HPV 16, 18, 31, 33, 35, 39, 45, 51, 52, $56,58,59,66$, and 68 ) either as a cocktail or individually. Six type specific oligonucleotides were used as a cocktail to detect the low risk HPV (HPV 6, 11, 40, 42, 43, and 44). Serial dilutions $(1: 10)$ of the 20 cloned high risk/low risk HPV types (0.01 fg to $10 \mathrm{pg}$ ) were used to 
Table 1 Distribution of 14 high risk (HR) HPV types determined by general primer polymerase chain reaction enzyme immunoassay in CIN (cervical intraepithelial neoplasia) smears with different grades

\begin{tabular}{|c|c|c|c|c|c|c|c|c|c|c|c|c|}
\hline $\begin{array}{l}\text { Histology } \\
\text { (mean age, } \\
\text { range) }\end{array}$ & $H R H P V$ & $H P V 16$ & $H P V 18$ & $H P V 31$ & $H P V 33$ & HPV 39 & $H P V 45$ & $H P V 51$ & $H P V 56$ & $H P V 58$ & $H P V 66$ & $H P V X$ \\
\hline $\begin{array}{l}\text { CIN I } \\
(\mathrm{n}=49) \\
29.0 \text { years } \\
(17-52)\end{array}$ & $\begin{array}{l}23 \\
(47 \%)\end{array}$ & $\begin{array}{c}6 \\
(12 \%)\end{array}$ & 0 & $\begin{array}{l}1 \\
(2 \%)\end{array}$ & $\begin{array}{l}3_{(2 \mathrm{x})} \dagger \\
(6 \%)\end{array}$ & $\begin{array}{l}1 \\
(2 \%)\end{array}$ & $\begin{array}{l}2 \\
(4 \%)\end{array}$ & $\begin{array}{l}2 \\
(4 \%)\end{array}$ & $\begin{array}{l}2 \\
(4 \%)\end{array}$ & $\begin{array}{l}4_{(2 \mathrm{x})}^{\mathrm{a}} \dagger \\
(8 \%)\end{array}$ & $\begin{array}{l}1 \\
(2 \%)\end{array}$ & $\begin{array}{l}1 \\
(2 \%)\end{array}$ \\
\hline $\begin{array}{l}\text { CIN II } \\
(\mathrm{n}=31) \\
30.8 \text { years } \\
(18-54)\end{array}$ & $\begin{array}{l}24 \\
(77 \%)\end{array}$ & $\begin{array}{l}11 \\
(35 \%)\end{array}$ & $\begin{array}{l}2_{(2 \mathrm{x})} \dagger \\
(6 \%)\end{array}$ & $\begin{array}{l}6.5_{(1 \mathrm{x})} \dagger \\
(21 \%)\end{array}$ & $\begin{array}{l}2 \\
(6 \%)\end{array}$ & 0 & $\begin{array}{l}0.5_{(1 \mathrm{x})} \dagger \\
(2 \%)\end{array}$ & 0 & 0 & 0 & $\begin{array}{l}1 \\
(3 \%)\end{array}$ & $\begin{array}{l}1 \\
(3 \%)\end{array}$ \\
\hline $\begin{array}{l}\text { CIN III } \\
(\mathrm{n}=34) \\
31.1 \text { years } \\
(16-57)\end{array}$ & $\begin{array}{l}33 \\
(97 \%)\end{array}$ & $\begin{array}{l}25_{(2 \mathrm{x})} \dagger \\
(74 \%)\end{array}$ & $\begin{array}{l}0.5_{(1 \mathrm{x})} \dagger \\
(1 \%)\end{array}$ & $\begin{array}{l}4.5_{(1 \mathrm{x})} \dagger \\
(13 \%)\end{array}$ & $\begin{array}{l}3 \\
(9 \%)\end{array}$ & 0 & 0 & 0 & 0 & 0 & 0 & 0 \\
\hline
\end{tabular}

HPV 35, 52, 59, and 68 were not detected in CIN independently of the grade of the lesion.

High risk HPV positive: CIN I $v$ CIN II, $\mathrm{p}=0.01$; CIN I $v$ CIN III, $\mathrm{p}<0.001$; CIN II $v$ CIN III, $\mathrm{p}=0.02$.

$H P V 16$ positive: CIN I $v$ CIN II, $\mathrm{p}=0.03$; CIN I $v$ CIN III, $\mathrm{p}<0.001$; CIN II $v$ CIN III, $\mathrm{p}=0.01$.

$H P V 31$ positive: CIN I $v$ CIN II, $\mathrm{p}=0.05$; CIN I $v$ CIN III, $\mathrm{p}=0.04$.

HPVX, HPV types negative for all 14 individually tested high risk HPV types.

tThe number of double infections is indicated in subscript parentheses.

verify the sensitivity while establishing the PCR-EIA. For a detailed description see reports by Jacobs et al. ${ }^{1925}$

The PCR-EIA, which measures optical density values, can be used to monitor the amount of the PCR amplicons. In this study we determined the amount of HPV 16 specific PCR products by semiquantitative PCR-EIA. The sensitivity of this HPV 16 PCR-EIA was determined by serial dilutions of cloned HPV 16 plasmid DNA and different amounts of a cell line with only one HPV 16 copy ( $\mathrm{SiHa}$ ). Each experiment was done twice independently. The mean values of each sample were used to estimate the virus load of HPV 16 positive CIN. The total number of cervical cells was not determined. To measure virus load in a more accurate way, a quantitative PCR would have to be applied.

STATISTICAL ANALYSES

Statistical analysis was done using $\chi^{2}$ or Fisher's exact test, when frequencies were smaller than 5. For estimation of HPV 16 virus load in CIN I, CIN II, or CIN III, the WilcoxonMann-Whitney $U$ test was applied, excluding the high risk HPV negative cases (fig 1). A p value of $<0.05$ was considered significant either for $\alpha$, or if indicated, for $\alpha$ multiple.

\section{Results}

Overall, 114 women with a mean age of 30.1 years (range 16 to 57 years) were enrolled in the study. Histological evaluation of the biopsies showed CIN I in 49 cases (mean age 29.0 years, range 17 to 52 ), CIN II in 31 cases (mean age 30.8 years, range 18 to 54), and CIN III in 34 cases (mean age 31.1 years, range 16 to 57 ) (table 1). Two double infections were found in each CIN I, CIN II, and CIN III, and an individual HPV type within a double infection was counted as 0.5 (table 1 ).

Low risk HPV types (HPV 6, 11, 40, 42, 43, and 44 ) were detected in $6 \%$ of CIN I (three of 49) and in no CIN II/III cases, independent of the method used - that is, conventional general primer PCR followed by Southern blot or the
Table 2 Comparison of polymerase chain reaction (PCR) enzyme immunoassay with radioactive Southern blot hybridisation of GP5+/bioGP6+PCR products for the detection of genital HPV types in patients with different grades of cervical intraepithelial neoplasia (CIN)

\section{$G P-P C R$}

\begin{tabular}{|c|c|c|c|c|c|}
\hline$\overline{E I A H R / L R}$ & $S B G P+$ & CIN I & CIN II & CIN III & Total \\
\hline Positive & Positive & 25 & 24 & 32 & 81 \\
\hline Negative & Negative & 16 & 5 & 1 & 22 \\
\hline Positive & Negative & 1 & 0 & 1 & 2 \\
\hline Negative & Positive & 7 & 2 & 0 & 9 \\
\hline Total & & 49 & $3 \overline{1}$ & 34 & 114 \\
\hline \multicolumn{2}{|c|}{$\begin{array}{l}\text { Overall agreement rate } \\
\kappa \text { Value }\end{array}$} & $84 \%$ & $94 \%$ & $97 \%$ & $\begin{array}{l}90 \% \\
0.75\end{array}$ \\
\hline
\end{tabular}

EIA, enzyme immunoassay; GP, general primer; GP+, positive for at least 19 different genital low risk and high risk HPV genotypes; HR, high risk; LR, low risk; SB, Southern blot.

PCR-EIA using a cocktail of six specific DIG labelled oligonucleotides (table 2). The sensitivity of the 14 high risk and six low risk HPV types by PCR-EIA was between 10 and 200 HPV copies, depending on the HPV type analysed by dilution experiments of each cloned HPV type (data not shown).

A linear logarithm relation between OD values and HPV copy number was found for the HPV types used as a cocktail or individually within the range $(O D \leqslant 2)$. Relative $O D$ values (OD minus cut off) between $\geqslant 0$ and 2.0 correspond to 10 and $1000 \mathrm{HPV} 16$ DNA copies, respectively, by the semiquantitative PCR-EIA. The agreement rate of high risk/low risk HPV positivity in cervical smears by Southern blot of general primer PCR amplicons hybridised with a general radioactively labelled probe and the PCR-EIA was $84 \%$ in CIN I, 94\% in CIN II, $97 \%$ in CIN III, and $90 \%$ for all 114 CIN lesions ( $\kappa$ value 0.75 ) (table 2). Seven CIN I and two CIN II were positive for genital HPV types detected by the radioactive Southern blot but negative for the high risk/low risk HPV types tested by PCR-EIA. One CIN I and one CIN III were borderline positive for HPV 16 by PCR-EIA (OD $=0.39$ and 0.17 ) and negative by the radioactive Southern blot (table 2).

Further analysis was restricted to the results obtained by PCR-EIA. High risk HPVs were 


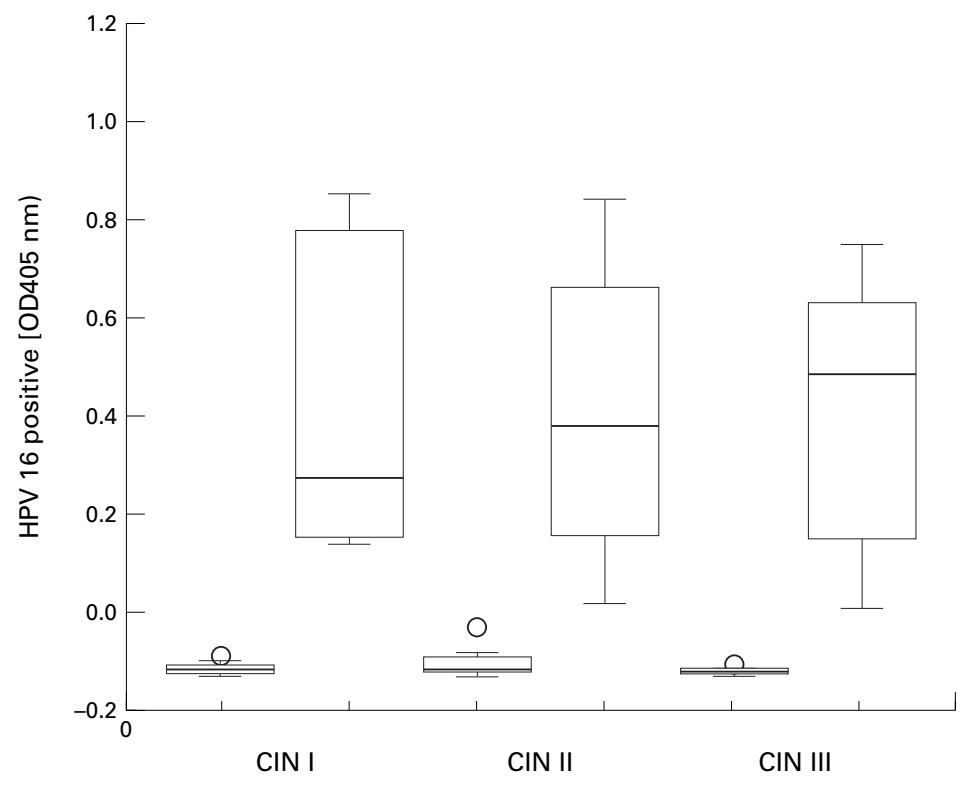

\begin{tabular}{|c|c|c|c|c|c|c|}
\hline & HPV16- & HPV16+ & HPV16- & HPV16+ & HPV16- & HPV16+ \\
\hline Number & 43 & 6 & 20 & 11 & 8 & 26 \\
\hline HPV16 positive & \multicolumn{2}{|c|}{$12 \%$} & \multicolumn{2}{|c|}{$35 \%$} & \multicolumn{2}{|c|}{$74 \%$} \\
\hline Median & \multicolumn{2}{|c|}{0.28} & \multicolumn{2}{|c|}{0.38} & \multicolumn{2}{|c|}{0.49} \\
\hline Third quartile & \multicolumn{2}{|c|}{0.76} & \multicolumn{2}{|c|}{0.66} & \multicolumn{2}{|c|}{0.63} \\
\hline
\end{tabular}

Figure 1 Histology $v$ virus load of HPV 16 DNA amount estimated by semiquantitative general primer polymerase chain reaction enzyme immunoassay (GP-PCR-EIA). Each experiment was done twice independently, and further analysis was done using the mean values of each sample. The values were calculated as the mean of duplicate experiments and $S D$ was $<15 \%$. The Wilcoxon-Mann-Whitney $U$ test (significance for a multiple $=0.05$ ) was applied, excluding the high risk HPV negative cases. CIN I v CIN II: NS, $p=0.73$; CIN I v CIN III: NS, $p=0.89)$; CIN II v CIN III: NS, $p=1.0$. HPV 16-, HPV 16 negative; HPV 16+, HPV 16 positive; OD, optical density.

detected in $47 \%$ of CIN I, $77 \%$ of CIN II, and $97 \%$ of CIN III $(\mathrm{p} \leqslant 0.02$ ) (table 1 ). HPV types $39,51,56$, and 58 were found in CIN I, exclusively (between $2 \%$ and $8 \%$ ). HPV 16 and HPV 31 were detected in $12 \%$ and $2 \%$ of CIN I, $35 \%$ and $21 \%$ of CIN II, and $74 \%$ and $13 \%$ of CIN III, respectively $(\mathrm{p} \leqslant 0.03$ and $\mathrm{p} \leqslant 0.04)$.

The virus load of all HPV 16 positive CIN lesions was estimated by the HPV 16 specific semiquantitative PCR-EIA. HPV 16 was found in six of 49 cases of CIN I, 11 of 31 cases of CIN II, and 26 of 34 cases of CIN III (fig 1). The virus load of HPV 16 positive CIN was similar for all grades indicated by the median $(0.28,0.38$, and 0.49$)$ and the third quartile $(0.76,0.66$, and 0.63$)$ for CIN I, CIN II, and CIN III, respectively.

\section{Discussion}

Amplification based technologies, such as PCR, are the most sensitive techniques for detecting HPV DNA in cervical smears. The primary goal of this study was to test the sensitivity of the non-radioactive general primer PCR enzyme immunoassay in cervical smears of histologically confirmed CIN lesions to detect 14 different high risk HPV types. For the radioactive Southern blot a general probe of $150 \mathrm{bp}$ was used to detect at least 19 different high risk/low risk HPV types, compared with 14 different oligonucleotides (30-mers), each specific for one HPV type used to detect the 14 high risk HPV by PCR-EIA. An overall agreement rate of $96 \%$ $(\kappa=0.90)$ between radioactive Southern blot hybridisation, with a general probe developed to distinguish between HPV positive and HPV negative samples, and high risk/low risk HPV PCR-EIA of the same PCR products was recently reported for 417 cytomorphologically abnormal cervical smears. ${ }^{19}$ We also found excellent agreement $(\kappa=0.75)$ between the same radioactive Southern blot hybridisation method and high risk/low risk PCR-EIA with GP5+/bioGP6+ PCR amplicons of two independent reactions in cervical smears of patients with different grades of CIN.

In The Netherlands, high risk HPV positivity of $53 \%$ in 34 CIN I, $75 \%$ in 32 CIN II, and $96 \%$ in 28 CIN III was found by the general GP5/GP6 and type specific (TS) PCR for the high risk HPVs $(16,18,31) .{ }^{26}$ In another study from The Netherlands, in which cervical smears from 1373 patients were analysed by GP5/GP6 and TS PCR, ${ }^{27} \mathrm{CIN}$ was diagnosed by cytology and the overall HPV positivity rate was $72 \%$ in 971 CIN I, $85 \%$ in 295 CIN II, and $100 \%$ in 107 CIN III. Low risk HPV types (6, and 11) were detected in less than $4 \%$, independently of CIN grade. In a study from The Netherlands using a PCR system, HPV 6/ $11,16,18,31$, or 33 were found in $44 \%$ of CIN I, $69 \%$ of CIN II, and $86 \%$ of CIN III, respectively. ${ }^{28}$ Low risk HPV types (6, and 11) were detected in less than $4 \%$ of the different CIN grades. We found similar high risk HPV prevalence rates, with $47 \%$ in CIN I, $77 \%$ in CIN II, and $97 \%$ in CIN III. Low risk HPV types (HPV 6, 11, 40, 42, 43, and 43) were only detected in $6 \%$ of CIN I (three of 49 ) in our study. Thus HPV prevalence and HPV distribution in CIN seems to be comparable in the different European countries when similar HPV detection systems are applied.

In a study from Japan, 220 frozen biopsies of CIN lesions were analysed by a restriction fragment polymorphism (RFLP) Southern blot assay. ${ }^{29}$ Twenty seven different HPV types were found and the overall HPV prevalence was $94 \%$ in CIN I, $100 \%$ in CIN II, and $93 \%$ in CIN III. The low risk HPV types 6 and 11 were not detected. In our study a similar HPV distribution pattern was found for the HPV types $16,18,31,33,39,56,59$, and 66 . In contrast, in Japan HPV 51, 52, and 58 were detected in between $2 \%$ and $20 \%$ of CIN II/III, respectively. ${ }^{29}$ In our study these HPV types were detected in CIN I exclusively. This discrepancy may be the result of geographically different prevalence rates for the various HPV genotypes. ${ }^{4}$ The overall HPV prevalence in cervical smears of CIN II and CIN III was similar (77\% and $97 \%$ ), but lower in CIN I (47\%). This phenomenon may be explained by misclassification - the interobserver and intraobserver agreement for the histological diagnosis of CIN I was poor, in contrast to a good agreement for CIN II/III. ${ }^{30}$ CIN I lesions are most likely to be misread in older women. ${ }^{31}$ In our study, only 14 of 49 patients (29\%) were older than 35 years and a large number of biopsies from elderly women cannot explain 
the low HPV positivity in CIN I. Another explanation may be the differences in the cell material used. Matsukura and Sugase ${ }^{29}$ used biopsies of CIN lesions for HPV detection, rather than the cervical smears used in our study.

In a worldwide study, 1035 cervical cancer lesions were investigated for the presence of 26 HPV types by a general primer PCR based method, and 932 were included in the analysis. ${ }^{4}$ The most prevalent HPV types in 86 cervical cancers from Europe were HPV 16 (65\%), HPV 18 (8\%), HPV 31 (6\%), HPV 52, 68 (4\%), HPV 45, 56 (2\%), and HPV 33, 35, $58(1 \%)$, whereas HPV 39, 51, and 59 were not detected. We found a similar HPV distribution in CIN III: HPV 16 (74\%), HPV $31(13 \%)$, HPV 33 (9\%), HPV 18 (1\%). HPV 35, 52, 59, and 68 were not detected in CIN, independently of the grade of the lesion, and HPV types $39,51,56$, and 58 were detected in CIN I exclusively. CIN I is expected to regress spontaneously in about $60 \%$ of cases, to persist in $30 \%$, and to progress to invasive cervical cancer in only $1 \% .^{32}$ Therefore HPV 39, 51, and 59 seem to have a lower oncogenic potential and may play a minor role in the progression of CIN lesions.

Previous studies with semiquantitative PCR or quantitative hybrid capture systems showed an increasing amount of high risk HPV DNA in cervical smears with increasing severity of the lesions, ${ }^{933}{ }^{34}$ indicating that the severity of the lesion is correlated with the presence of high risk HPV genomes. In two studies analysing patients with different grades of CIN a significantly higher virus load of HPV 16 was found in CIN III $v$ CIN I by a semiquantitative PCR detection method. ${ }^{17}{ }^{18}$ However, topological distribution of HPV DNA molecules in cervical tissues is not well explained, and distribution of viral copies may vary for the individual HPV types. For HPV 16 we found a similar virus load in CIN I, CIN II, and CIN III using the semiquantitative PCR-EIA. This discrepancy with respect to previous studies may be caused by the small number of HPV 16 positive CIN I lesions analysed in our study compared with the studies of Cuzick et $a l .{ }^{17}{ }^{18}$ Interestingly, our results are in accordance with a recent study where a quantitative HPV 16 DNA PCR-EIA was used and where the HPV 16 virus load in progressive and regressive precancer lesions did not differ. ${ }^{35}$ Thus further studies analysing the virus load in high risk HPV types with new quantitative assays are warranted to solve some of these inconsistencies.

Our data indicate that the new high risk HPV general primer PCR-EIA has high sensitivity for identifying patients with CIN II/III. Nevertheless, larger trials need to be performed to assess the value of HPV testing in cervical cancer screening programmes.

We thank C J L M Meijer, J M M Walboomers, and MV Jacobs for their support in HPV testing by general primer PCR enzyme immunoassay. We acknowledge C Greinke and K Teller for Dürst for critical reading of the manuscript. HPV clones of types
$6 \mathrm{~b}, 11,16,18,33,40,68$ were kindly provided by $\mathrm{H}$ zur Hausen and E-M de Villiers (Heidelberg, Germany); HPV 44 and 52 by J M M Walboomers (Amsterdam, The Netherlands); HPV 31 by A Lorincz (Silver Spring, Maryland, USA); HPV 58 and 59 by T Matsukura (Tokyo, Japan); HPV 45 by K Shah (Baltimore, Maryland, USA); HPV 51 by G Nuovo (New York, USA); and HPV 39, 42, and 66 by $\mathrm{G}$ Orth (Paris, France). Cloned HPV types 35, 43, and 56 were obtained from the ATTCC (Rockville, Maryland, USA). This work was supported by a grant of the DFG, Germany (grant No SCHN 294/5-1).

1 International Agency for Research on Cancer. IARC monographs on the evaluation of carcinogenic risks to humans. Human papillomaviruses. Lyon: IARC, 1995;64.

2 de Villiers EM. Human pathogenic papillomavirus types: an update. Curr Top Microbiol Immunol 1994;186:1-12.

3 Vandate. Curr Top Microbiol Immunol 1994;186:1-12. Van Ranst M, Kaplan JB, Burk RD. Phylogenetic classifi-
cation of human papillomaviruses: correlation with clinical cation of human papillomaviruses: correlation

4 Bosch FX, Manos MM, Munoz N, et al. Prevalence of human papillomavirus in cervical cancer: a worldwide perspective. International Biological Study on Cervical Cancer (IBSCC) Study Group. $\mathcal{F}$ Natl Cancer Inst 1995;87:796-802.

5 Lorincz AT, Reid R, Jenson AB, et al. Human papillomavirus infection of the cervix: relative risk associations of 15 common anogenital types. Obstet Gynecol 1992;79:32837.

6 Kjaer SK, van den Brule AJ, Bock JE, et al. Human papillomavirus - the most significant risk determinant of 601-6.

7 Melkert PW, Hopman E, van den Brule AJ, et al. Prevalence of HPV in cytomorphologically normal cervical smears, as of HPV in cytomorphologically normal cervical smears, as
determined by the polymerase chain reaction, is agedetermined by the polymerase chain reac

8 Reid R, Greenberg MD, Lorincz A, et al. Should cervical cytologic testing be augmented by cervicography or human papillomavirus deoxyribonucleic acid detection? $A m$ f Obstet Gynecol 1991;164:1461-71

9 Cuzick J, Szarewski A, Terry G, et al. Human papillomavirus testing in primary cervical screening. Lancet 1995;345: 1533-6.

10 Schneider A, Zahm DM, Kirchmayr R, et al. Screening for cervical intraepithelial neoplasia grade $2 / 3$ : validity of cytologic study, cervicography and human papillomavirus detection. Am f Obstet Gynecol 1996;174:1534-41.

11 Cox JT, Lorincz AT, Schiffman MH, et al. Human papillomavirus testing by hybrid capture appears to be useful in triaging women with a cytologic diagnosis of atypical triaging women with a cytologic diagnosis of atypical
squamous cells of undetermined significance. Am $\mathcal{f}$ Obstet squamous cells of undetermecol 1995;172:946-54.

12 Hatch KD, Schneider A, Abdel Nour MW. An evaluation of human papillomavirus testing for intermediate- and high-risk types as triage before colposcopy. Am $\mathcal{F}$ Obstet Gynecol 1995;172:1150-7.

13 Remmink AJ, Walboomers JMM, Helmerhorst TJ, et al. The presence of persistent high-risk HPV genotypes in dysplastic cervical lesions is associated with progressive disease: natural history up to 36 months. Int $\mathcal{F}$ Cancer 1995; 61:306-11.

14 Bergeron C, Barrasso R, Beaudenon S, et al. Human papillomaviruses associated with cervical intraepithelial neoplasia. Great diversity and distinct distribution in low- and high-grade lesions. Am $\mathcal{F}$ Surg Pathol 1992;16:641-9.

15 Lungu O, Sun XW, Felix J, et al. Relationship of human papillomavirus type to grade of cervical intraepithelial neopapillomavirus type to grade of cer
plasia. fAMA 1992;267:2493-6.

16 van den Brule AJ, Walboomers JMM, Du Maine M, et al. Difference in prevalence of human papillomavirus genotypes in cytomorphologically normal cervical smears is associated with a history of cervical intraepithelial neoplasia. Int $\mathcal{F}$ Cancer 1991;48:404-8.

7 Cuzick J, Terry G, Ho L, et al. Human papillomavirus type 16 in cervical smears as predictor of high-grade cervical cancer. [Published erratum appears in Lancet 1992;9:339: 1182]. Lancet 1992;339:959-60.

18 Cuzick J, Terry G, Ho L, et al. Type-specific human papillomavirus DNA in abnormal smears as a predictor of high-grade cervical intraepithelial neoplasia. $\mathrm{Br} 7$ Cancer 1994;69:167-71.

19 Jacobs MV, Snijders PJ, van den Brule AJ, et al. A general primer GP5+/GP6+-mediated PCR-enzyme immunoassay method for rapid detection of 14 high-risk and 6 low-risk human papillomavirus genotypes in cervical scrapings. $f$ human papillomavirus genotype

20 Riotton G, Christofferson WM, Lunt R. Cytology of the female genital tract: international histological classification of tumours. Geneva, WHO, 1973.

21 Richart RM. Cervical intraepithelial neoplasia. Pathol Annu 1973;8:301-28.

22 Crum CP, Nuovo GJ. Sternberg S, eds. The cervix. In: Diagnostic surgical pathology. New York: Raven Press, 1994: 2055-90.

23 de Roda Husman AM, Walboomers JMM, van den Brule AJC, et al. The use of general primers GP5 and GP6 elongated at their 3 ends with adjacent highly conserved sequences improves human papillomavirus detection by PCR. F Gen Virol 1995;76:1057-62.

24 Jacobs MV, de Roda Husman AM, van den Brule AJ, et al. Group-specific differentiation between high- and low-risk human papillomavirus genotypes by general primer-
mediated PCR and two cocktails of oligonucleotide probes. f Clin Microbiol 1995;33:901-5. 
25 Jacobs MV, van den Brule AJC, Snijders PJF, et al. A non-radioactive PCR enzyme-immunoassay enables a rapid identification of HPV 16 and 18 in cervical scrapes after GP5+/6+ PCR. F Med Virol 1996;49:223-9.

26 Cromme FV, Meijer CLJM, Snijders PJ, et al. Analysis of MHC class I and II expression in relation to presence of HPV genotypes in premalignant and malignant cervica lesions. Br f Cancer 1993;67:1372-80.

27 de Roda Husman AM, Walboomers JMM, Meijer CLJM, al. Analysis of cytomorphologically abnormal cervical scrapes for the presence of 27 mucosotropic human papillomavirus genotypes, using polymerase chain reaction. Int $f$ Cancer 1994;56:802-6.

28 Burger MPM, Hollema H, Pieters WJLM, et al. Predictive value of human papillomavirus type for histological diagnosis of women with cervical abnormalities. $B M F$ 1995;310:94-5.

29 Matsukura T, Sugase M. Identification of genital human papillomaviruses in cervical biopsy specimens: segregation papillomaviruses in cervical biopsy specimens: segregation Int $\mathcal{F}$ Cancer 1995;61:13-22.
30 Robertson AJ, Anderson JM, Beck JS, et al. Observer variability in histopathological reporting of cervical biopsy specimens. I Clin Pathol 1989;42:231-8.

31 Jovanovic AS, McLachlin CM, Shen L, et al. Postmenopaual squamous atypia: a spectrum including "pseudokoilocytosis." Mod Pathol 1995;8:408-12.

32 Ostor AG. Natural history of cervical intraepithelial neoplasia: a critical review. Int f Gynecol Pathol 1993;12: 186-92.

33 Nindl I, Greinke C, Zahm D-M, et al. Human papillomavirus distribution in cervical tissues of different morphology as determined by hybrid capture assay and PCR. Int $\mathcal{F}$ Gynecol Pathol 1997;16:197-204.

34 Schiffman $\mathrm{MH}$, Kiviat NB, Burk RD, et al. Accuracy and interlaboratory reliability of human papillomavirus DNA testing by hybrid capture. $\mathcal{F}$ Clin Microbiol 1995;33:545-50.

35 Jacobs MV, van Beek J, Snijders PJF, et al. Quantitative HPV 16 DNA Detection in cervical smears by PCR-EIA Workshop, 1997:256. 